
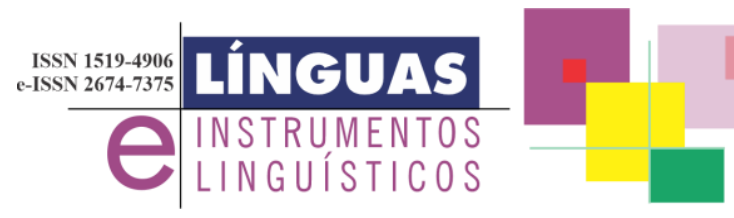

DOI: $10.20396 /$ lil.v24i48.8667916

\title{
Funcionamento discursivo e enunciativo do sinal de pessoa para a comunidade surda
}

\section{Discursive and enunciative functioning of the person sign for the deaf community}

\author{
Nilce Maria da Silva* \\ UNEMAT
}

\section{Benício Bruno da Silva** \\ UNIFAL}

Resumo: Propomos discutir, neste texto, sobre a atribuição do sinal de pessoa para os sujeitos surdos, no embate entre estar no espaço de enunciação que já tem um nome definido pelo Estado e a necessidade de um sinal para ser identificado pela comunidade surda. Este texto se constitui em um espaço de reflexão sobre a atribuição de nome próprio por meio de sinal por e para pessoas surdas e ouvintes na comunidade surda na cidade de Cáceres/MT. Ao refletir sobre a nomeação do sujeito surdo por um determinado sinal por meio da Língua Brasileira de Sinais, no espaço de enunciação movimentado por duas línguas Língua Portuguesa e Libras - e falantes e sinalizantes destas línguas, respectivamente, mobilizamos os pressupostos teórico-metodológicos da Semântica da Enunciação, desenvolvidos por Guimarães (2002, 2004, 2005), para estabelecer uma relação entre essas duas línguas no espaço de enunciação brasileiro. 
Palavras-chave: Libras, Sinal, Nome próprio, Comunidade surda, Espaço de enunciação.

Abstract: In this text, we propose to discuss the attribution of the person sign to deaf subjects, in the struggle between being in the enunciation space that already has a name defined by the State and the need for a sign to be identified by the deaf community. It constitutes a space for reflection on the attribution of a proper name through a sign by and for deaf and hearing people in the deaf community in of the city of Cáceres/MT. When reflecting on the naming of the deaf subject by a certain sign through the Brazilian Sign Language, in the space of enunciation moved by two languages - Portuguese and Libras - and speakers and signers of these languages, respectively, we mobilized the theoretical-methodological assumptions of the Semantics of Enunciation, developed by Guimarães (2002, 2004, 2005), to establish a relationship betwenn these two languages in the space of brazilian enunciation.

Palavras-chave: Libras, Sign, Proper name, Deaf community, Space of enunciation.

\section{Espaço de enunciação: Língua Portuguesa e Língua Brasileira de Sinais}

Como as línguas funcionam sempre em relação a outras línguas, neste artigo, em especial, vamos abordar a nomeação do sujeito surdo por um determinado sinal por meio da Língua Brasileira de Sinais, no espaço de enunciação movimentado por, pelo menos, duas línguas Libras e Língua Portuguesa - e falantes e sinalizantes destas línguas, respectivamente. Tomo para reflexão os estudos de Guimarães (2002, 2004, 2005) para, a partir deles, estabelecer uma relação entre essas duas línguas.

Ao pontuar que o Brasil é um país multilíngue, formado por mais de 200 línguas, tendo-se de um lado o Português e do outro as línguas indígenas e as de imigração (e de fronteira, e de escravos, entre outras), Guimarães $(2004$, p. 48) assinala que "a relação entre estas línguas é regulada pelo fato de que o Português é língua oficial do Brasil e a 
língua nacional do povo brasileiro". Gostaríamos de acrescentar que, nesse conjunto de línguas, encontra-se a Língua Brasileira de Sinais Libras, que não faz parte das línguas indígenas nem das de imigração, e que se caracteriza por um sistema linguístico de natureza visualmotora, reconhecida pelo Estado Brasileiro como língua da comunidade surda do Brasil, conforme Lei $n^{\circ}$ 10.436, de 22/04/2002.

Nesta lei, destaca-se:

Artigo $1^{\circ}$ É reconhecida como meio legal de comunicação e expressão a Língua Brasileira de Sinais - Libras e outros recursos de expressão a ela associados.

É a partir do estabelecimento desta legalidade, que os surdos conquistaram o espaço de enunciação para a prática da Libras, além de estender este direito para os diferentes locais e instituições e a garantia da obrigatoriedade de acesso pela Libras.

Guimarães (2002, p. 18) define os espaços de enunciação como "espaços de funcionamento de línguas, que se dividem, redividem, se misturam, transformam por uma disputa incessante. São espaços habitados por falantes, ou seja, por sujeitos divididos por seus direitos ao dizer e aos modos de dizer", entendendo que são nesses espaços que a enunciação é tomada como uma prática política social. Essa prática se dá, então, quando se assume a palavra neste espaço dividido por línguas e sujeitos, e isto só é possível porque há línguas e há falantes, ou dito de outro modo, não há falantes sem língua e não há língua sem falantes.

Estamos considerando que o espaço de enunciação brasileiro, além de ser constituído pela Língua Portuguesa e mais outras cerca de duzentas línguas e seus falantes, é constituído também pela Libras e seus sinalizantes. Ou seja, como existe a língua de sinais nesse espaço de enunciação, existem também os sinalizantes dessa língua. Assim, do mesmo modo que o espaço atribui as línguas para seus falantes, a Libras é atribuída para os sinalizantes surdos que irão sinalizá-la, a partir de uma determinada regulação.

Para Guimarães (ibidem, p. 17), a relação entre falantes e línguas é sempre uma relação inscrita no político ${ }^{1}$, enquanto "contradição que instala o conflito no centro do dizer", e porque é um espaço determinado e particularizado pela deontologia ${ }^{2}$ do dizer. No caso da Libras, 
estendemos essa relação posta entre falantes e línguas para e entre os sinalizantes e a língua de sinais, considerando que nesse espaço de tensão e de contradição, a Libras e os sinalizantes se constituem. Essa relação, então, coloca falantes, sinalizantes e línguas em tensão, em contradição, em constante embate, não no sentido pessoal, individual, mas, especialmente, na tensão que o político instala.

Assim como a Língua Portuguesa se apresenta dividida, na tensão entre modos de dizer, a Libras também se encontra dividida. Sinalizar a Libras é sinalizar não uma língua somente, é sinalizar uma língua materna e/ou uma língua oficial. Tomemos um exemplo. Tanto os surdos que ainda não passaram por processo de escolarização, como aqueles que não participam das comunidades surdas, sinalizam a língua diferente dos surdos escolarizados e participantes dessas comunidades. Para o sinal mãe, por exemplo, os primeiros sinalizam-no indicando uma característica da mãe, como cabelo liso ou crespo, ou algo que a mãe usa, como brinco. O sinal mãe para os surdos escolarizados é um sinal composto: sinal de mulher seguido do sinal de bênção: "mão horizontal fechada, palma para a esquerda, polegar distendido. Passar o lado do polegar sobre a bochecha, em direção ao queixo. Então, fechar a mão, palma para baixo e beijar seu dorso" 3 . Esse sinal é considerado um sinal padrão da Libras, ao contrário do sinalizado pelo primeiro grupo de surdos.

Assim, os sinalizantes, divididos por seus direitos ao dizer e aos modos de dizer, se encontram distribuídos desigualmente no espaço de enunciação da Libras. Essa divisão para estes sujeitos marca a relação deles com a língua, ou seja, alguns podem dizer certas coisas e não outras, outros podem falar de certos lugares e não de outros. Essa divisão inscreve o sujeito surdo no espaço determinado e particularizado pela deontologia do dizer, conforme vimos em Guimarães.

Como a Língua Portuguesa é a língua oficial do Estado, sinalizar/falar" "4 uma outra língua - a Libras - é estar no centro dessa tensão, dessa contradição. O sujeito da Libras está regulado pela língua da nação, mas se inscreve na materialidade da língua de sinais, de modalidade viso-motora, para poder sinalizar, para poder dizer, para poder compreender o que está sendo dito em Língua Portuguesa. O poder sinalizar, aqui, corresponde, na língua de modalidade oralauditiva, a falar, a tomar a palavra. 
Na tensão que o político instala, no espaço de enunciação regulado pela normatividade da Língua Portuguesa, por ser esta "o idioma oficial da República Federativa do Brasil (Artigo 13 da Constituição Federal, de 1988), o sinalizante, aqui no Brasil, ao escrever, deve fazê-lo em Língua Portuguesa, não em Libras, como apresentado no parágrafo único da Lei 10.436:

Parágrafo Único: A Língua Brasileira de Sinais Libras não poderá substituir a modalidade escrita da Língua Portuguesa.

Esta regulação da lei é um modo de estabelecer relação entre as línguas para os sujeitos, apontando que todos podem falar, sinalizar, no sentido da oralidade, mas todos devem saber ler e escrever o idioma oficial do Estado.

Como o sujeito da Libras está também regulado pela língua do Estado, ele é nomeado, pela primeira vez, pelo locutor-pai, que o inclui no Estado, no espaço de enunciação da Língua Portuguesa. Mas, para poder dizer e ser dito, por outros surdos, no espaço onde a Libras funciona, ele é nomeado por um sinal pessoal. O nome é, assim, um indício fundamental de que o sujeito da Libras se encontra continuamente atravessado/constituído enunciativa e discursivamente pelas duas línguas - Língua Portuguesa e Libras.

Além de a pessoa surda ter o nome jurídico regulado pela Língua Portuguesa e o sinal pessoal regulado pela Libras, é interessante observar que alguns sinais de pessoa inscrevem o sujeito nas duas línguas, no espaço enunciativo das duas línguas. O sinal, constituído por parâmetros específicos da Libras, como o movimento, é atravessado pela primeira letra do nome oficial, escrito em Língua Portuguesa, o nome oficial para o Estado.

Tomemos o exemplo do sinal pessoal de Thainá, da comunidade surda de Cáceres/MT. Para realizar o sinal de Thainá, deve-se configurar a mão direita em T e, ao movimentar a mão em direção ao queixo, encostar a ponta do dedo indicador no lado direito do queixo. Assim, temos a configuração de mão em $\mathbf{T}$, caractere da Língua Portuguesa, que faz parte do conjunto de configurações de mão constitutivo dos parâmetros da Libras. É então a configuração de mão articulada com o ponto de articulação e com o movimento que se 
constrói o sinal para Thainá. Estamos, assim, diante de um embate em que o sinalizante está dividido por sua relação com as duas línguas, entendendo que no espaço de enunciação a Língua Portuguesa convive com a Libras.

Temos também sinais de pessoa da comunidade surda de CáceresMT que apresentam o sinal regulado somente pela Libras. Tomemos o exemplo do sinal pessoal de Monique. A letra $\mathbf{M}$ do nome de Monique não faz parte da formulação do sinal. Neste caso, o sinal construído para nomear Monique leva em conta inicialmente a marca do sorriso que se junta a uma determinada configuração de mão (duas mãos fechadas com o dedo indicador estendido), ponto de articulação e à expressão fisionômica. Para sinalizar Monique, então, deve-se levar as duas mãos (já configuradas) simultaneamente ao rosto e, com as pontas dos indicadores, tocar os dois lados do rosto, um pouco abaixo de cada lado dos lábios, ao mesmo tempo em que sorri (expressão fisionômica alegre).

Consideramos, assim, que as relações entre as duas línguas se movimentam - Língua Portuguesa e Libras - e os sujeitos destas línguas, os falantes e os sinalizantes, respectivamente, no espaço de enunciação brasileiro, ora se aproximam, ora se distanciam. Vimos, também, que a Libras procura reconfigurar seu lugar neste espaço de enunciação: a exigência enunciativa de uma (re)nomeação por sinal para afirmar o pertencimento na comunidade surda é um indício importante deste movimento de demarcar o lugar da Libras e dos sujeitos surdos.

Este texto, então, se constitui em um espaço de reflexão sobre a atribuição de nome próprio por meio de sinal por e para pessoas surdas e ouvintes em uma comunidade surda na cidade de Cáceres/MT. Vamos discutir sobre a atribuição do sinal de pessoa para os sujeitos surdos, no embate entre estar no espaço de enunciação que já tem um nome definido pelo Estado e a necessidade de um sinal para ser identificado pela comunidade surda.

\section{O sinal de pessoa para o sujeito surdo}

Nas comunidades surdas cada pessoa surda é nomeada por um sinal, e atribuir um sinal é uma prática comum entre os surdos, a partir da qual a pessoa passa a ser identificada socialmente na comunidade surda. 
Normalmente, as pessoas ao se conhecerem socialmente, apresentam-se por meio do nome próprio dado do lugar da paternidade. Com as pessoas surdas, a apresentação se constitui de duas maneiras: soletrando o nome jurídico através da datilologia ${ }^{5}$ e sinalizando o sinalnome - o nome visual, em língua de sinais. Para exemplificar, vejamos a imagem.

Figura 1- Apresentação do nome em datilologia e do sinal pessoal do Sr. Nelson ${ }^{6}$

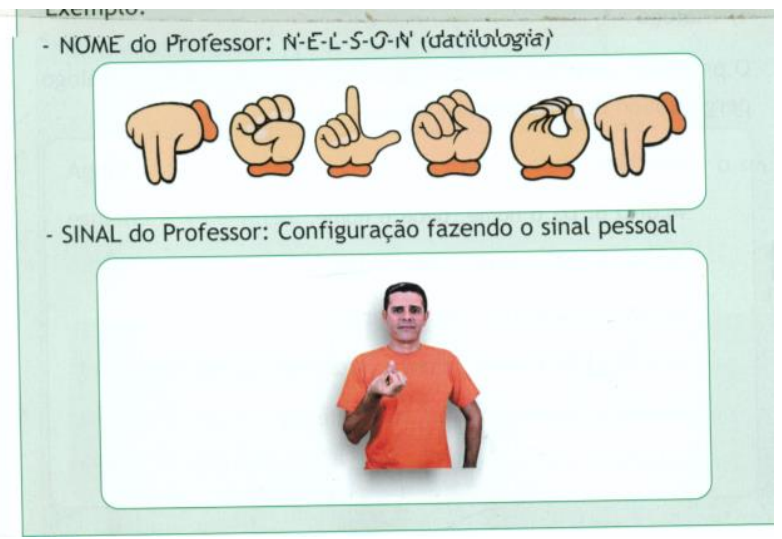

O nome jurídico do professor N-E-L-S-O-N, soletrado letra por letra, a partir das configurações de mão, representa as letras do alfabeto da Língua Portuguesa e exemplifica um modo de apresentação de uma pessoa surda. Outro modo é o sinal de pessoa do professor Nelson, formulado na Língua Brasileira de Sinais, a partir de parâmetros dessa língua como a configuração de mão, local de articulação do sinal e movimento ${ }^{7}$. O sinal pessoal de Nelson é feito com a mão direita, palma para cima, dedos indicador, médio, anelar e mindinho dobrados tocando no meio do dedo polegar, em frente ao corpo, movimentando-a para frente e para trás, duas vezes.

Para Silva et al. (2007, p. 18), este sinal que é "denominado de sinal pessoal ou somente $\underline{\text { sinal }}^{8}$, costuma-se dizer que se trata de um nome visual, um batismo, para dar início à participação na comunidade surda”. Neste estudo, assumimos a denominação sinal pessoal ou sinal de pessoa para diferir de sinal, uma vez que o vocábulo sinal, somente, refere-se ao "conjunto de sinais que compõem o léxico da Língua 
Brasileira de Sinais", ou seja, seu sinalário (STUMPF, 2005, p. 36) (grifo nosso).

A Língua Brasileira de Sinais é uma língua basicamente produzida pelas mãos, assim como as demais línguas de sinais. Segundo Quadros e Karnopp (2004, p. 51), "as mãos, articuladores primários dessa língua, se movimentam no espaço em frente ao corpo e articulam sinais em determinadas locações nesse espaço". O que é reconhecido por palavra ou item lexical nas línguas oral-auditivas denomina-se sinal nas línguas espaço-visuais. (SACKS, 1998).

Ferreira-Brito assinala que o sinal é formado por três principais parâmetros: a configuração da(s) mão(s) $(\mathrm{CM})$, o ponto de articulação (PA) e o movimento (M) e os conceitua

A configuração da(s) mão(s) são as diversas formas que a(s) mão(s) toma(m) na realização do sinal; o ponto de articulação é o espaço em frente ao corpo ou uma região do próprio corpo onde os sinais são realizados e o movimento é definido como um parâmetro complexo porque envolve uma vasta rede de formas e direções, desde os movimentos internos da mão, os movimentos do pulso, os movimentos direcionais no espaço até conjuntos de movimentos do mesmo sinal (FERREIRA-BRITO, 1995, pp. 36-38).

Tomando como objeto de análise a sinalização de pessoas surdas, queremos, neste estudo, refletir sobre como o sinal é atribuído à pessoa surda, em uma comunidade surda, a partir da concepção de sinal de pessoa como um "nome de batismo". Neste sentido, no próximo item, vamos refletir sobre o processo de atribuição do sinal de pessoa para os sujeitos surdos, no embate entre estar no espaço de enunciação que já tem um nome definido pelo Estado e a necessidade de um sinal para ser identificado pela comunidade surda.

Para analisar a nomeação pelo sinal, mobilizamos os estudos sobre nomes próprios desenvolvidos por Guimarães (2002), em Semântica do Acontecimento, e também os estudos dos antropônimos, realizados por Amaral (2008, 2010 e 2011), e dos apelidos discutidos por Gladkova (2002), Holland (1990) e Skipper, Jr. e Leslie (1990). 


\section{Nomes jurídicos, apelidos e sinal de pessoa}

Como toda pessoa, o surdo também é nomeado pela primeira vez pelo locutor-pai, que o incluiu no Estado, no espaço de enunciação da Língua Portuguesa. Os nomes próprios de pessoa são legitimados por uma ordem jurídica, baseada no Código Civil Brasileiro9. No capítulo I, o Art. $2^{\circ}$ nos informa que a personalidade civil da pessoa começa a partir do nascimento com vida, e o Art. 16 reza que toda pessoa tem direito ao nome, nele compreendidos o prenome e o sobrenome, ou seja, está posta a obrigatoriedade jurídica de atribuir nome à pessoa.

É necessário dizer ainda que o ato de registrar e nomear uma criança, previsto na Lei $\mathrm{n}^{\circ} 6.015$, de 31/12/1973, é, prioritariamente, uma obrigação do pai. Guimarães (ibidem, p. 36) assinala que o "registro de nascimento, um texto sustentado pela lei, nomeia e inclui o nomeado no Estado, com as obrigações e direitos advindos dessa inclusão". Deste modo, esse sujeito nomeado passa a ser identificado para o Estado por um nome próprio. A obrigatoriedade regida por uma lei só torna possível a existência da criança para a sociedade depois de seu registro.

O surdo é nomeado pela primeira vez pelo locutor-pai, com um certo nome para a comunidade ouvinte. Ao ser caracterizado pela condição da surdez, este sujeito passa a precisar de um sinal pessoal para ser identificado pela comunidade surda. $\mathrm{O}$ nomeado não perde o nome jurídico (não há substituição completa do nome jurídico) e, o processo de nomeação por um sinal pode levar em conta o próprio nome jurídico ou um outro nome que lhe tenha sido atribuído em um meio ouvinte ou surdo em outras circunstâncias, isto é, um apelido.

Segundo Pimenta e Quadros (2008, p.7), "os surdos brasileiros se batizam por meio de sinais. Na verdade, é um ritual que acontece quando um surdo ou um ouvinte entra no grupo surdo ou passa a ter contato com surdos". Ou seja, esse batismo configura-se como um acontecimento de linguagem para o nomeado, pois a partir daí o surdo passa a ter uma identidade e a estabelecer uma relação de pertencimento na comunidade surda. É o sinal que captura esse indivíduo, e o coloca como sujeito na comunidade de surdos.

Toda criança, após ter um nome, se torna única, individualizandose, pois, podemos ver funcionando 
o papel do nome no processo de identificação social. Ou seja, como a unicidade que se busca para o nome é efeito da identificação: você é você e não é nenhum outro. Assim é possível referi-lo, interpelá-lo, responsabilizá-lo, etc., "sem possibilidade de erro, de equívoco" (GUIMARÃES, 2005, p. 40). (grifos do autor).

Assim, pelo efeito de unicidade do nome próprio, cada pessoa tem um nome através do qual ela é identificada socialmente. O nome próprio tem sua história, sendo construído e reconstruído enunciativamente, no espaço regulado pela Língua Portuguesa, e é isso que produz o efeito de identificação do sujeito nomeado.

O sinal de cada um dos surdos funciona como forma de não só particularizá-lo, como também de identificá-lo na comunidade surda. Assim como o nome próprio significa a inclusão da pessoa no Estado, o sinal significa a inclusão da pessoa, na sua condição de surdez, na comunidade surda da cidade em que ele reside. É interessante destacar que o sinal que o inclui, nessa comunidade específica, também o acompanha durante a sua vida social em comunidades surdas do Brasil e de outros países.

Na nomeação em Língua Portuguesa, o próprio sujeito não pode escolher seu nome próprio, como afirma Guimarães (2002, p. 36) em relação ao nome próprio jurídico. Para a comunidade surda, a escolha do sinal também não é uma "escolha"; a "escolha" do sinal se dá também por agenciamento enunciativo específico, ou seja, ao escolher um sinal, o sujeito recorta como memoráveis as configurações ou parâmetros disponíveis da língua de sinais, próprios de sua época. Observamos que não há repetição de sinais em si, na sua formulação completa, na sua totalidade. O que há é uma recorrência de uma determinada configuração de mão. Por exemplo, uma mesma configuração de mão é retomada para sinalizar Alberto e Fábio e outra, igual, para sinalizar Álvaro e Monique. No entanto, o que particulariza e identifica Alberto e Fábio, Monique e Álvaro, é a diferença de movimento do sinal pessoal de um e de outro.

Diferentemente da primeira nomeação, da qual a criança não participa da construção do nome próprio, em função das convenções sociais que determinam o modo de nomear alguém, na comunidade 
surda, o surdo a ser sinalizado pode interferir, sugerir, discordar do sinal que está sendo formulado. Uma outra nomeação pelo sinal pode ocorrer quando o nomeado considerar o sinal fora dos padrões e das práticas aceitáveis por ele mesmo ou pela comunidade surda. Vamos analisar um exemplo de um sinal pessoal que se alterou.

Os primeiros sinais de pessoa dos sujeitos surdos Alberto e Fábio, atribuídos pela comunidade surda, se configuraram como inadequados por tomarem uma característica do corpo para constituir o sinal. $\mathrm{O}$ primeiro sinal de Alberto - ao fazê-lo com as duas mãos abertas, cada uma de um lado do quadril, e movimentando as mãos e o quadril com um rebolado - inscreve-se numa memória de corpo de mulher, de nádegas grandes, próprias da mulher. Para Fábio, o primeiro sinal ombros caídos, e movimentando o corpo assemelhando ao andar de um gorila - rememora o tipo físico de macaco.

Essas nomeações, ao inscreverem os surdos numa memória de corpo de mulher, com nádegas grandes, e do tipo físico do macaco, operam negativamente na designação dos sujeitos surdos. Pelas recorrências, pela reconstituição contínua desses sinais, que podem expô-los ao riso e ao ridículo, é que se evidenciou a necessidade de uma nova nomeação, de um novo sinal de pessoa para os dois sujeitos.

$\mathrm{Na}$ formulação do novo sinal, há um outro memorável ${ }^{10}$ que vai afetar a determinação desse sinal. A "escolha" do sinal vai se justificar pela leveza do movimento para Alberto e por fortes movimentos das mãos, ou seja, pela força, para Fábio. Assim, esses novos aspectos vão produzir um efeito de sentido positivo. É o sinal que vai produzir esse efeito, a partir das características de cada um deles.

O sinal de Alberto passa a ser realizado a partir das letras do nome: A e T. Para sinalizar o novo sinal faz-se configuração de mão direita em A, movimenta-a levemente para a direita, e finalizando com a $\mathrm{CM}$ em T, no espaço em frente ao corpo. O novo sinal de Fábio é realizado da seguinte maneira: mão direita fechada, com o braço de forma horizontal, palma para a esquerda, palma do polegar tocando os demais dedos - e movimenta o braço direito, de baixo para cima, da direção do quadril até o peito, indicando força.

Ao serem nomeados por um outro sinal, um novo sentido vai se constituindo. Agora é um memorável que os inscreve, que marca uma identificação, algo que diz sobre eles. Do Alberto - é o efeito de sentido produzido pelo movimento das letras A e T no espaço que significa, 
porque diz dele, do nome dele, e não de algo exterior a ele. Para Fábio, o sinal significa porque produz o efeito de sentido de força, e isto é algo que particulariza o novo sinal.

O sinal do Leandro ilustra uma alteração/modificação do processo de sinalização, a partir da reivindicação de pertencimento do nomeado como parte dos que compõem o locutor-nomeador. O primeiro sinal, configurado com as duas mãos abertas, tocando simultaneamente as duas orelhas, de trás para a frente, foi alterado passando a ser enunciado somente com a mão direita, com o movimento de tocar somente a orelha direita, de trás para a frente, uma única vez.

Na comunidade surda, o sinal que é dado, na primeira nomeação, pode sofrer mudanças ou alterações/modificações no decorrer da vida do surdo, como exemplificado no processo de sinalização de Alberto, Fábio e Leandro.

Estas reflexões sobre a nomeação pelo sinal nos levam a entender que o sujeito nomeado passou a ter outros nomes, além do nome jurídico dado pelo locutor-pai. Ou seja, a pessoa passa a ser identificada também por outros nomes no decorrer da sua vida social. No caso de nosso estudo, esses nomes concorrem no espaço onde forças se dividem, ora o nome próprio jurídico, do Português do Brasil, ora o sinal pessoal, da Libras.

Em estudos sobre antropônimos, Amaral (2008, p. 79) define apelido como o "nome que substitui o nome civil, criado geralmente por um indivíduo diferente do portador do nome próprio e que frequentemente alude a uma característica física ou intelectual. Pode ser ou não depreciativo". E este autor considera que os apelidos, tanto quanto os prenomes, os sobrenomes e os hipocorísticos, integram o conjunto dos antropônimos (2010, p.3).

Skipper, Jr. e Leslie (1990, p. 253), na apresentação da edição especial do Journal of the American Name Society sobre apelidos de pessoas, afirmam que "pela maioria das definições, um apelido pode ser um nome que é adicionado ou que substitui um nome real ou pode ser uma forma curta ou preferida do nome real"11.

Holland Jr. (1990, p. 256), nessa mesma edição, em estudo sobre As muitas faces dos apelidos, afirma que os apelidos são usados de diferentes maneiras, por diferentes grupos sociais e não é possível entender a abrangência dessa nomeação nas suas respectivas sociedades 
sem o estudo da estrutura demográfica e social, o meio cultural, a partir do qual surge o seu uso.

No estudo sobre os apelidos de presidentes dos Estados Unidos da América, Gladkova (2002, p. 2) analisa alguns apelidos, a partir de partes/elementos do nome e de expressões que assinalam que o apelido, para ela, significa um nome alternativo de uma pessoa e que os outros sabem que não é o nome real do nomeado. Diz, ainda, que o apelido captura uma característica da pessoa, e serve para fazer alusão aos presidentes no que diz respeito a alguns aspectos, como a relação paternal, o respeito que os usuários sentem em relação ao apelidado, familiaridade com a pessoa nomeada, entre outros. Isto é, os apelidos são usados mais para classificar e identificar os presidentes e não para substituir os nomes oficiais.

Amaral (2008) e Gladkova (2002) afirmam que os apelidos fazem alusão a alguma característica do apelidado e é também o que dizem Pimenta e Quadros $(2008$, p. 7) sobre a nomeação de pessoas surdas: "os surdos olham para a pessoa e identificam alguma característica que seja específica da pessoa e lhe dão um sinal".

O sinal da pessoa surda a acompanha em todas as situações da vida cotidiana e assemelha-se ao nome jurídico. O sinal não substitui o nome, não ocupa o lugar do nome, mas anda pari passu com o nome, em todas as situações em que as duas línguas são colocadas em relação. Ou seja, em situação de presença de duas línguas e do sujeito surdo, este se apresenta e se identifica, soletrando o nome jurídico, por meio do alfabeto datilológico, letra por letra, e, em seguida, apresenta-se com o seu sinal. No entanto, quando a Libras é a língua única das relações sociais, o surdo pode se apresentar com o seu sinal pessoal, no primeiro momento.

Levando-se em conta essas análises, é que defendemos que o sinal pessoal funciona também como um outro nome próprio para o sujeito surdo. Não há uma validade "jurídica" no sentido mais amplo de jurídico, tal como entendido por Ducrot[por a referência] em "Esboço de uma teoria polifônica da enunciação". Além do quê, não podemos esquecer que quando se fala em apelido, se pensa em primeiro lugar em uma relação em uma mesma língua, e não em línguas diferentes, embora isto possa acontecer; mas, se acontece, geralmente não é em um mesmo espaço de enunciação, isto é, o apelido em nova língua se dá em outro espaço, regulado por outra língua de Estado. Neste caso, ele não 
tem implicações jurídicas, não é necessário para a inscrição da pessoa na comunidade, embora possa ajudar a legitimar esta inscrição.

Para assinar quaisquer documentos, desde um título de eleitor a uma prova, de uma ficha de um crediário a um recibo de correio, é em língua portuguesa que o surdo enuncia. Já quando participa da comunidade surda, tanto local como em qualquer outro lugar, de uma apresentação informal até uma formal, em caso de conferencista de um evento científico, é o sinal pessoal que o identifica e o particulariza.

O processo de nomeação pelo sinal pessoal dos surdos de Cáceres se assemelha à construção de alguns apelidos em línguas orais no que se refere às características do apelidado. A enunciação do sinal flagra marcas do corpo, características físicas, sorriso, cabelo liso, cabelo longo, dedo quebrado, marca de nascença, pomo de adão, habilidade para dançar, levantar bicicleta etc. No entanto, o apelidado em língua oral geralmente não participa da criação de seu apelido. E há, na língua de sinais, uma priorização do efeito de descrição sobre o efeito de metaforização, isto é, o que é nomeado rememora o fato de ser gordo na comunidade surda terá o sentido de gordo, e não, como nas comunidades orais, a possibilidade de ter o sentido de gordo, ou metaforicamente, o de magro - um gordo pode ter o apelido de "Magrão", por exemplo.

Tomemos um dos sinais de uma pessoa da comunidade surda de Cáceres para exemplificar o sinal construído a partir de uma marca do corpo. Na formulação do sinal pessoal, Bruno foi capturado por uma pequena verruga que ele tem perto da orelha direita. Essa marca serviu como ponto de referência para ser o local de articulação do sinal. Assim, na construção do sinal, a essa marca que representa o ponto de articulação, juntaram-se a configuração de mão e o movimento. Assim, o sinal de Bruno passa a ser formulado com a mão direita com os dedos mínimo, anelar e médio fechados, palma do polegar tocando a palma do dedo indicador nas pontas (configuração de mão que lembra uma pinça), tocar levemente, uma vez, (movimento) a marca perto da orelha (ponto de articulação). É esse ato que o identifica, que o particulariza.

$O$ gesto de sinalizar é constitutivo do sentido do sinal, ou seja, significa dentro de uma história que determina o processo de sinalização e do funcionamento do sinal. É um sujeito sinalizado na Libras. É um sinal de pessoa que funciona porque está inscrito nesta 
língua. O sinal pessoal é um modo de identificar os sujeitos surdos na comunidade surda.

Outro aspecto da nomeação dos surdos pelo sinal de pessoa referese aos diferentes lugares enunciativos. Na comunidade surda de Cáceres, três lugares se constituíram: Na Associação dos Amigos e Pais de Excepcionais (Apae), no início dos anos 90, e na Escola Estadual Prof. Natalino Ferreira Mendes e na Associação de Surdos de Cáceres $(\mathrm{ASCÁ})^{12}$, na década atual. Diferentemente da obrigatoriedade do locutor-pai em nomear o filho, nas cenas enunciativas de nomeação nessas instituições, a escolha dos sinais ocorreu em diferentes lugares sociais de dizer. $\mathrm{O}$ nomeador-sinalizante, uma determinada pessoa surda, fluente em Libras, assume o lugar social de nomeador-lídersurdo para nomear/sinalizar o outro surdo, ou seja, na nomeação dos surdos da comunidade de Cáceres, o sinalizante só pode nomear outro se estiver predicado pelo lugar social de sinalizante, de líder da comunidade surda e de ser surdo. E o lugar de locutor-líder-nomeador (sinalizante-líder-surdo) não é tomado somente pelo líder, mas é partilhado pelo conjunto da comunidade surda. Ou seja, o sinal pessoal pode ser construído coletivamente.

Ao "construir/escolher" um sinal pessoal, o locutor-nomeado, sob a liderança do locutor-líder-nomeador (sinalizante-líder-surdo), instaura um agenciamento enunciativo específico, constituído pela memória de nomeação em sinais, que produz recorrentemente um discurso que produz o efeito de descritividade entre o nome e o nomeado para compor a nomeação. A escolha dos sinais, então, é regulada pela normatividade própria da Libras.

$\mathrm{O}$ sinal pessoal funciona como nome próprio porque é este sinal pessoal que o identifica enquanto sujeito e cidadão surdo, sinalizante de LIBRAS e pertencente à comunidade surda do Brasil. Este sinal pessoal funciona como possibilidade de inclusão, de pertencimento jurídico à comunidade surda, sem o qual este pertencimento não se dá. No ritual de nomeação, a cena enunciativa também tem sua particularidade em Libras, pela inclusão de um conjunto de locutores-nomeadores sob a condução de um líder surdo, e sinalizante proficiente em Libras.

Os sinais são formulados no espaço de enunciação brasileiro, "espaços de funcionamento de línguas, que se dividem, redividem, se misturam, transformam por uma disputa incessante", como nos lembra Guimarães (2002, p. 18) e já apontado no início deste texto. Há, nesse 
processo de sinalizar o surdo pelo sinal, a relação entre a Libras e a Língua Portuguesa. Como convivem sinalizantes e a Libras no espaço de enunciação da Língua Portuguesa e de falantes desta língua, e como a própria LIBRAS se constrói também na relação com o Português do Brasil, ao nomear o surdo, seu sinal pessoal se configura na relação entre as duas línguas. A constituição do sinal pessoal se faz em Libras na relação com o Português: é a configuração de mão em T, em A, em $\mathrm{N}$, etc., que rememora às letras do alfabeto, que, por sua vez, são as letras iniciais do nome jurídico do sujeito a ser nomeado. O diagrama a seguir apresenta o modo de funcionamento de nomeação nessas duas línguas:

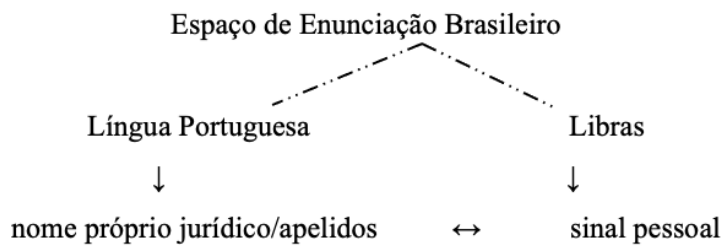

$O$ fato de haver necessidade de um novo nome, em LIBRAS, atribuído em ritual próprio à comunidade surda, indica o embate enunciativo entre a Língua Brasileira de Sinais e a Língua Portuguesa. $\mathrm{O}$ falante tem um duplo estatuto, marcado pelos dois nomes, dois modos de identificação pessoal, em processos de nomeação distintos, na língua oral e na língua de sinais. Não basta "traduzir" o nome civil da língua oral. É preciso recriar uma identidade, pertencer à comunidade de surdos.

\section{Referências}

AMARAL, E. T. R. Nomes próprios: análise de antropônimos do espanhol escrito. Tese (Doutorado em Letras), Universidade de São Paulo - USP, Faculdade de Filosofia, Letras e Ciências Humanas, SP: 2008. Disponível em: http://eduamaralbh.wordpress.com/ dissertacaoe-tese Acesso: 01/03/2012.

AMARAL, E. T. R. Classificação dos usos de antropônimos no português escrito. Fórum linguístico. Florianópolis, v. 7, n. 2, jul-dez, 2010, p. 74-92. 
AMARAL, E. T. R. Contribuições para uma tipologia de antropônimos do português brasileiro. ALFA 55(1), São Paulo, 2011, p. 63-82.

CAPOVILLA, F. C. RAPHAEL, W. D. \& MAURICIO, A C. L. Novo Deit-Libras: Dicionário enciclopédico ilustrado trilíngue da língua de sinais brasileira. 2. ed. Ilustrações de Silvana Marques. São Paulo: EdUSP: Inep: CNPq: Capes, 2009 v. I: sinais de A a L e v. 11: sinais de $\mathrm{M}$ a Z.

CASTRO, V. M. Apelidação e circulação dos apelidos em Cláudio (MG): um estudo enunciativo sobre nomes próprios. Projeto de mestrado. Texto mimeo. 2011.

Código Civil Brasileiro. Lei $\mathrm{n}^{\circ} 10.406$ de 10.01.2002. Disponível em: http://www.jucepa.pa.gov.br/downloads/docs/pdf/Novo_codigo_civil. pdf. Acesso em: 15/08/2011.

DUCROT, O. O dizer e o dito. Campinas, Pontes, 1984.

FERREIRA-BRITO, L. Por uma gramática de línguas de sinais. Rio de Janeiro: Tempo Brasileiro: UFRJ, 1995.

GLADKOVA, A. The semantics of nicknames of the american presidents. 2002.

GUIMARÃES, E. Semântica do acontecimento. 2. ed. Campinas: Pontes, 2002.

GUIMARÃES, E. Letras no 26: língua e literatura - limites e fronteiras. Programa de Pós-graduação em Letras. PPGL-UFSM. 2004, p. 53-62.

GUIMARÃES, E. Letras $\mathbf{n}^{\mathbf{0}}$ 27: língua e literatura - limites e fronteiras. Programa de Pós-graduação em Letras. PPGL-UFSM. 2004, p. 47-53.

HOLLAND, TJ Jr. The many faces of nicknames. Names. 38 (4), p. 255-272.

Lei Federal 6.015 de 1973. Acesso em: 15 de agosto de 2011. Disponível em: http://legislacao.planalto.gov.br/legisla/legislacao.

Lei $n^{\circ}$ 10.436, de 24 de abril de 2002. Disponível em: http://www.planalto.gov.br/civil _03/Leis/2002/L10436.

PIMENTA, N. e QUADROS, R. M. de. Curso de Libras. 3. ed. Rio de Janeiro, LSB vídeo, 2008.

QUADROS, R. M. de \& KARNOPP, L. B. Língua de sinais brasileira: estudos linguísticos. Porto Alegre: Artmed, 2004.

SACKS, O. Vendo vozes: uma viagem ao mundo dos surdos. Trad. Laura Teixeira Motta. São Paulo: Companhia das Letras, 2010. 
SILVA, F. I. da et al. Aprendendo Língua Brasileira de Sinais como segunda língua. Caderno pedagógico, nível básico. CEFET/SC, 2007, p. 18.

SKIPPER, J. K, Jr. e LESLIE, Paul L. The systematic study of personal nicknames: a small step forward. Names. 38 (4), p. 253-254.

STUMPF, M. Aprendizagem de escrita de Língua de Sinais pelo sistema SignWriting: Língua de sinais no papel e no computador. Tese (Doutorado em Informática na Educação), Universidade Federal do Rio Grande do Sul - UFRGS, CINTED, PO: 2005.

\section{Notas}

* Professora da Faculdade de Educação e Linguagem e do Programa de Mestrado Profissional em Letras (ProfLetras) da Universidade do Estado de Mato Grosso UNEMAT - em Cáceres.

** Professor do Instituto de Ciências Humanas e Letras da Universidade Federal de Alfenas - UNIFAL

${ }^{1}$ Guimarães (2005, p.17) define política, baseado nas reflexões de Rancière (1995) sobre o político na filosofia.

${ }^{2}$ Em nota (2002, p. 18), Guimarães diz que toma essa noção na perspectiva de Ducrot $(1972,89)$ que utiliza a palavra "deontologia" ao descrever o ato ilocucional: ao dar uma ordem a uma pessoa, essa é colocada numa situação jurídica nova, sendo essa jurisdição considerada como uma deontologia própria do ato linguístico, ou seja, a pessoa se vê obrigada a realizar o ato em decorrência da fala do outro.

${ }^{3}$ CAPOVILlA, F. C. RAPHAEL, W. D. \& MAURICIO, A C. L. Novo Deit-Libras: Dicionário enciclopédico ilustrado trilíngue da língua de sinais brasileira. 2. ed. Ilustrações de Silvana Marques. São Paulo: EdUSP: Inep: CNPq: Capes, 2009 v. 1: sinais de A a L e v. 2: sinais de M a Z.p. 1429.

${ }^{4}$ Em relação à língua de sinais, assumimos que sinalizar a língua de sinais é semelhante ao falar a língua oral, e o sinalizante dessa língua é semelhante ao falante, conforme Stumpf (2005, p. 36).

${ }^{5}$ Usar do alfabeto manual para nomear objetos, pessoas, etc., conforme definido por Capovilla (2009).

6 PIMENTA, N. e QUADROS, R. M. de. Curso de Libras. 3. ed. Rio de Janeiro, LSB vídeo, 2008, p. 11

${ }^{7}$ Veremos estes conceitos a seguir.

${ }^{8}$ Destaques dos autores.

9 http://www.jucepa.pa.gov.br/downloads/docs/pdf/Novo_codigo_civil.pdf. Lei $\mathrm{n}^{\mathrm{o}}$ 10.406, de 10.01.2002

${ }^{10} \mathrm{O}$ memorável se inscreve na temporalidade do acontecimento, em que "presente e futuro próprios do acontecimento funcionam por um passado que os faz significar. $\mathrm{Ou}$ 
seja, esta latência de futuro que, no acontecimento projeta sentido, significa porque o acontecimento recorta um passado como memorável" (GUIMARÃES, Semântica do Acontecimento, 2002, p. 12).

${ }^{11}$ By most definitions, a nickname may be a name which is added to or which replaces a real name or it may be a short or pet form of the real name.

${ }^{12}$ A APAE era a escola em que todos os alunos com alguma deficiência frequentavam, na cidade de Cáceres, na década de 1980. Atualmente, quase todos os alunos surdos de Cáceres-MT estudam na Escola Est. Natalino Ferreira Mendes, no ensino fundamental, por ser uma das poucas que tem intérprete de Libras. Fora do âmbito escolar, os surdos participam da Associação de Surdos (ASCÁ), criada e mantida por eles. 